\title{
Arthrobacter chlorophenolicus sp. nov., a new species capable of degrading high concentrations of 4-chlorophenol
}

\author{
Karolina Westerberg, ${ }^{1}$ Annelie M. Elväng, ${ }^{1}$ Erko Stackebrandt ${ }^{2}$ \\ and Janet $\mathrm{K}$. Jansson ${ }^{1,3}$
}

\begin{abstract}
Author for correspondence: Janet K. Jansson. Tel: +4685858 87 44. Fax: +4685858 8510 . e-mail: janet.jansson@sh.se
\end{abstract}

\footnotetext{
1 Department of Biochemistry, Stockholm University, S-10691 Stockholm, Sweden

2 DSMZ-Deutsche Sammlung von Mikroorganismen und Zellkulturen $\mathrm{GmbH}$, Mascheroder Weg 1b, 38124 Braunschweig, Germany

3 Södertörns högskola, Section for Natural Sciences, Box 4101, S-141 04 Huddinge, Sweden
}

\begin{abstract}
A micro-organism was isolated from soil which could grow on high concentrations [up to 350 p.p.m. (2.7 mM)] of 4-chlorophenol (4-CP). The isolate, designated strain $A^{\top}{ }^{\top}$, was obtained from a soil suspension that had been selectively enriched with gradually increasing concentrations of 4-CP. Strain A6 $^{\top}$ could also grow on several other para-substituted phenols. Characterization of strain $\mathrm{A6}^{\top}$ with respect to chemical, biochemical and morphological properties, 16S rDNA sequencing and DNA-DNA hybridization indicated that the isolate is a novel species within the genus Arthrobacter for which the name Arthrobacter chlorophenolicus sp. nov. is proposed. The type strain is DSM 12829'.
\end{abstract}

Keywords: Arthrobacter chlorophenolicus sp. nov., 4-chlorophenol, biodegradation, soil enrichment

\section{INTRODUCTION}

Bioremediation exploits the catabolic diversity of micro-organisms to transform contaminants into less harmful compounds. In this process, one can either use the micro-organisms already present at the site of contamination (intrinsic bioremediation) or inoculate with micro-organisms having special catabolic properties (bioaugmentation). Inoculation may be warranted when the intrinsic micro-organisms present at the location are not able to degrade the compound because of lack of suitable enzymes, or when the pollutant is so toxic that the intrinsic micro-organisms are inhibited (Timmis \& Pieper, 1999; Vogel, 1996).

Bioaugmentation, however, is not a straightforward technique, as there are many parameters to consider to ensure inoculant survival and efficacy (Liu \& Suflita, 1993; van Veen et al., 1997; Vogel, 1996). To assess the potential success of bioaugmentation, knowledge is required about inoculant survival and activity in the contaminated environment and how it is affected by external variables such as soil humidity and temperature (Liu \& Suflita, 1993; Vogel, 1996). Knowledge is also required about the chemical properties of

Abbreviation: 4-CP, 4-chlorophenol.

The GenBank accession number for the $16 \mathrm{~S}$ rDNA sequence of strain $A 6^{\top}$ is AF102267. the pollutant itself and its bioavailability (Liu \& Suflita, 1993; Vogel, 1996). The more that is known about these parameters, the easier it is to optimize bioaugmentation strategies and therefore to increase the chance of successful clean-up.

One pollutant which is a candidate for bioremediation is 4-chlorophenol (4-CP). 4-CP is a toxic and recalcitrant compound which is formed, for example, from chlorination of waste water, in pulp mills, from breakdown of herbicides such as 2,4-dichlorophenoxyacetic acid (Pritchard et al., 1987) and from anaerobic degradation of more highly chlorinated phenols, such as pentachlorophenol and 2,4,6-trichlorophenol (Madsen \& Aamand, 1992; Woods et al., 1989). The toxicity of 4-CP is reflected in the fact that although several microbial strains can degrade 4-CP, such as certain members of the genera Pseudomonas, Alcaligenes and Arthrobacter (Häggblom, 1990, 1992), degradation is usually limited to relatively low concentrations in the range of $20-100$ p.p.m. $(0.2-0.8 \mathrm{mM})$. This toxicity severely limits the potential for bioremediation of high concentrations of 4-CP, for example, at locations where the compound has accumulated over a period of time. Several other problems may also arise in a bioaugmentation scenario. For example, 4-CP degradation might be restricted to co-metabolism in the presence of an inducer, such as phenol (Hill et al., 1996), or dead-end meta- 
bolites may accumulate (Ihn et al., 1989; Wieser et al., 1994). Thus, when selecting a micro-organism for bioaugmentation, one needs to consider these potential problems. These hindrances may be overcome by genetically modifying existing strains, or by using selective enrichment to obtain adapted isolates with the desired catabolic properties.

Our aim was to isolate a micro-organism capable of degrading high concentrations of 4-CP for bioaugmentation of 4-CP contaminated soil. From a 4CP enrichment inoculated with soil, an isolate was obtained which was able to use high concentrations of 4-CP as sole source of carbon and energy. We have characterized the isolate as a novel species within the genus Arthrobacter and we propose the name Arthrobacter chlorophenolicus sp. nov.

\section{METHODS}

Culture conditions. Strain $\mathrm{A} 6^{\mathrm{T}}$ was grown at $23-28^{\circ} \mathrm{C}$ in a minimal medium $(\mathrm{GM})$ containing $\left(\mathrm{g} \mathrm{l}^{-1}\right): \mathrm{K}_{2} \mathrm{HPO}_{4}, 2 \cdot 1$; $\mathrm{KH}_{2} \mathrm{PO}_{4}, \quad 0 \cdot 4 ; \quad \mathrm{NH}_{4} \mathrm{NO}_{3}, \quad 0 \cdot 5 ; \quad \mathrm{MgSO}_{4} .7 \mathrm{H}_{2} \mathrm{O}, \quad 0 \cdot 2 ;$ $\mathrm{CaCl}_{2} .2 \mathrm{H}_{2} \mathrm{O}, 0.023 ; \mathrm{FeCl}_{3} .6 \mathrm{H}_{2} \mathrm{O}, 0.002$ (Alexander \& Lustigman, 1966). When higher cell densities were needed, yeast extract was added to a final concentration of $0 \cdot 1-0 \cdot 3 \%$ $(\mathrm{w} / \mathrm{v})$ as indicated. A stock solution of 4-CP (Acros) was prepared in distilled water at a concentration of $5-10 \mathrm{mg} \mathrm{ml}^{-1}$ and stored in the dark until use. For plates, 150 or 200 p.p.m. 4-CP was used and agar was added to a concentration of $1.5 \%$. GMY plates consisted of GM medium with $0.3 \%$ yeast extract. In liquid culture, strain $\mathrm{A} 6^{\mathrm{T}}$ was routinely grown at a $4-\mathrm{CP}$ concentration of 150 or 250 p.p.m., either shaken at 125 r.p.m. or without shaking. The temperature growth range was determined in LB broth.

Escherichia coli DH5 $\alpha$ was grown in LB broth or on LB plates at $37^{\circ} \mathrm{C}$, with $50 \mu \mathrm{g}$ ampicillin $\mathrm{ml}^{-1}$ when necessary.

Enrichment and isolation of a 4-CP-degrading isolate. Two grams of soil (Aridic haplustoll, sandy loam, $\mathrm{pH} 7 \cdot 5,68 \cdot 6 \%$ sand, $16 \cdot 1 \%$ silt, $15 \cdot 3 \%$ clay) was added to $300 \mathrm{ml} \mathrm{GM}$ medium containing 50 p.p.m. $4-\mathrm{CP}$. When $30-50 \%$ of the initial concentration had disappeared, as determined by spectrophotometric analysis (described below), new 4-CP was added. The addition of 4-CP was repeated over several cycles, up to a concentration of 350 p.p.m. $(2.7 \mathrm{mM})$. 4-CPdegrading bacteria were isolated from the enrichment culture on GM agar plates containing 300 p.p.m. 4-CP and $0 \cdot 3 \%$ yeast extract hardened at a slant with a top layer of GM agar, creating a diffusion gradient of 4-CP. 4-CP-resistant bacteria were isolated by cross-streaking against the 4-CP gradient on the gradient plates. Colonies resistant to high concentrations of 4-CP were purified by successive streaking on GM agar containing 200 p.p.m. 4-CP.

4-CP degradation analyses. The capability of strain $\mathrm{A} 6^{\mathrm{T}}$ to degrade different concentrations of 4-CP was determined in liquid cultures. Strain $A 6^{\mathrm{T}}$ cells were pregrown in GM medium with 150 p.p.m. 4-CP to stationary phase. The cells were harvested and inoculated into Erlenmeyer flasks containing $250 \mathrm{ml} \mathrm{GM}$ medium with a 4-CP concentration of 150-375 p.p.m. Triplicate treatments were performed for each 4-CP concentration level, except the 350 p.p.m. level which was performed in duplicate. Growth was measured by determining $\mathrm{OD}_{600}$ with a Beckman DU 640 spectrophotometer.
The 4-CP concentration in soil enrichments and liquid cultures was determined by pelleting cells and any soil particles by centrifugation, measuring the absorbance of the supernatant at $280 \mathrm{~nm}$ with a Beckman DU 640 spectrophotometer and relating the value to a standard curve prepared in sterile GM medium.

Growth of strain $A 6^{\top}$ on other aromatic compounds and pigment formation. Strain $\mathrm{A} 6^{\mathrm{T}}$ was grown to exponential phase with 4-CP as sole carbon source in GM medium. The cells were pelleted, washed twice and $\mathrm{OD}_{600}$ was adjusted to 0.03 in fresh GM medium. Triplicate $100 \mathrm{ml}$ cultures were set up with this cell suspension and the compounds to be tested as substrates were added to a final concentration of 100 p.p.m. Controls were prepared by using cell suspensions without substrate and uninoculated medium with substrate. The cultures were incubated at $28^{\circ} \mathrm{C}$ with shaking and $\mathrm{OD}_{600}$ was measured periodically. Cultures were monitored for at least three weeks. Growth on a substrate was inferred from $\mathrm{OD}_{600}$ measurements and in some cases also by monitoring the decrease in concentration of the substrate compound using spectrophotometry.

The ability of strain $A 6^{\mathrm{T}}$ to use 4-nitrophenol as sole source of nitrogen was tested in GM medium without nitrogen. The cultures were treated as above, except that an additional control was used in which strain $\mathrm{A} 6^{\mathrm{T}}$ was inoculated into nitrogen-free GM medium containing glucose to verify that 4-nitrophenol, and not traces of nitrogen in the medium, was indeed the nitrogen source.

Pigment production from different aromatic compounds by strain $\mathrm{A} 6^{\mathrm{T}}$ was investigated in liquid cultures. The cultures were prepared as described above. When the aromatic compound to be tested could be used for growth, as determined above, the cultures were incubated without shaking. For investigation of pigment production from compounds that could not be used for growth, yeast extract was added to $0 \cdot 1 \%(\mathrm{w} / \mathrm{v})$ to serve as a growth substrate and the cultures were incubated with shaking. The production of pigment was checked visually and also spectrophotometrically by scanning in the range of $200-800 \mathrm{~nm}$ with a Beckman DU 640 spectrophotometer.

Stability of the 4-CP-degrading phenotype. Cultures of strain $\mathrm{A} 6^{\mathrm{T}}$ were grown in triplicate in LB broth and upon reaching stationary phase the cultures were repeatedly transferred to fresh LB medium. After 10 consecutive transfers, the cells were plated on LB medium and the ability to grow on 4-CP was tested by transferring cells to 4-CP plates (150 p.p.m.) and fresh LB plates using sterile toothpicks.

Plasmid preparation. Three methods were used to attempt to isolate plasmids from strain $\mathrm{A}^{\mathrm{T}}$ : standard alkaline lysis minipreps (Sambrook et al., 1989), horizontal Eckhardt gels (Eckhardt, 1978) and a method developed for isolating plasmids from Arthrobacter oxydans (Brandsch \& Decker, 1984). Plasmids were isolated from E. coli using the Wizard Miniprep kit (Promega).

Metabolic characteristics and motility. BIOLOG tests were performed by Kirsten S. Jørgensen at the Finnish Environment Institute, Helsinki, Finland, as follows. The bacteria were pregrown twice on BUGM medium and inoculated to a GP MicroPlate (BIOLOG). The plates were read at 4 and $24 \mathrm{~h}$. No identification could be made at $4 \mathrm{~h}$ and the results reported are from the $24 \mathrm{~h}$ readout (BIOLOG GP database release 3.50).

Growth on additional substrates of taxonomic importance other than those tested by the BIOLOG system was assessed 
by growth in liquid cultures and/or on plates with the compound in question as sole carbon source at concentrations in the range $0 \cdot 2-0 \cdot 5 \%$. Formation of nicotine blue pigment was investigated on plates consisting of GM medium with $0 \cdot 2 \%(\mathrm{v} / \mathrm{v})$ nicotine and either 5 or $0.5 \mathrm{~g}^{-1}$ of yeast extract.

Motility was tested by the hanging drop method. For a description, see Meynell \& Meynell (1970).

Cellular fatty acid analysis. Whole-cell fatty acids were analysed by $M$. Salkinoja-Salonen at the Department of Applied Chemistry and Microbiology, University of Helsinki, Finland, as described by Väisänen et al. (1994).

Cell wall analysis. Cell wall diamino acids were analysed by TLC (Staneck \& Roberts, 1974). For detailed analysis of the peptidoglycan, purified cell wall preparations were obtained by the method of Schleifer \& Kandler (1972). The amino acids and peptides in cell wall hydrolysates were analysed by two-dimensional ascending TLC on cellulose plates using the solvent systems described by Schleifer \& Kandler (1972).

16S rDNA analysis. Genomic DNA preparation and standard cloning procedures were performed according to Sambrook et al. (1989). 16S rDNA from strain A6 ${ }^{\mathrm{T}}$ was PCR-amplified with the primers $\mathrm{rP} 2$ and $\mathrm{fD} 1$, modified from Weisburg et al. (1991) by removing the linker sequences. Genomic DNA (100 ng) was used in the PCR reaction together with $2.5 \mathrm{U}$ Pfu DNA polymerase (Stratagene). The resulting bluntended fragment of approximately $1500 \mathrm{bp}$ was ligated into SmaI-digested pUC19 (Pharmacia) and the resulting construct was transformed into $E$. coli DH5 $\alpha$. The outer parts of the insert were sequenced using the commercial primers M13 and M13 reverse (Amersham Pharmacia Biotech). To obtain the entire sequence, primer fD1 (described above) was used, in addition to the following specifically designed primers: SF3, 5'-CACCACTGGGGAATATTGCA-3' ; SF5, 5'-AGACTGGAATTCCTGGTGTA-3'. The sequencing reaction was performed using unlabelled primers and the dye termination method (Big Dye kit; Perkin-Elmer) and the DNA sequence was determined on an ABI 377 sequencer (PerkinElmer Applied Biosystems). One 350 bp stretch was previously sequenced by Frans deBrujin (Department of Microbiology and NSF centre for Microbial Ecology, Michigan State University, East Lansing, MI, USA) and this sequence was also included in the analysis. The resulting sequence was $1446 \mathrm{bp}$ (excluding the primer sequences), corresponding to positions 28-1493 of rDNA (E. coli numbering; Brosius et al., 1978).

To find out which micro-organisms were most closely related to strain $\mathrm{A}^{\mathrm{T}}$, the $16 \mathrm{~S} \mathrm{rDNA}$ sequence was used to search the RDP II database (Ribosomal Database Project, Michigan State University, USA; Maidak et al., 1994) and subjected to an NCBI (National Center for Biotechnology Information, Bethesda, MD, USA) BLAST search. Using the program CLUSTAL W 1.7, the 16S rDNA sequence of strain $\mathrm{A} 6^{\mathrm{T}}$ was aligned to the 16S rDNA of other Arthrobacter species and to closely related micro-organisms of other genera. $\mathrm{Myco-}$ bacterium tuberculosis was included as an outgroup. For the following phylogenetic analysis, the PHYLIP package was used (Felsenstein, 1993). A pairwise distance matrix was created from the aligned sequences with the program DNADIST, using the corrections for superimposed substitutions of Jukes \& Cantor (1969). Only homologous positions were used and sites where the alignment was ambiguous were excluded from the analysis. The program NEIGHBOR was subsequently used to create a phylogenetic tree, using the neighbour-joining method. Bootstrapping was performed using SEQBOOT, DNADIST, NEIGHBOR and CONSENSE (100 replicates) (Felsenstein, 1985).

DNA base composition. The $\mathrm{G}+\mathrm{C}$ content of the genome of strain $A 6^{\mathrm{T}}$ was determined by the melting temperature of the genomic DNA, courtesy of Vigdis Torsvik, Department of Microbiology, University of Bergen, Norway. Two parallel tests of the sample were performed, together with two controls, E. coli and 'Micrococcus lysodeikticus', and the $\mathrm{G}+\mathrm{C}$ content was calculated according to Mandel et al. (1970).

DNA-DNA hybridization. DNA from Arthrobacter oxydans DSM 20119 ${ }^{\mathrm{T}}$, Arthrobacter polychromogenes DSM 20136 and strain $\mathrm{A} 6^{\mathrm{T}}$ was isolated by chromatography on hydroxyapatite by the procedure of Cashion et al. (1977). DNADNA hybridization was carried out according to De Ley et al. (1970) with modifications as described by Huß et al. (1983) and Escara \& Hutton (1980) using a Gilford System 2600 spectrophotometer equipped with a Gilford 2527-R thermoprogrammer and plotter. Renaturation rates were computed by the program TRANSFER.BAS (Jahnke, 1992).

\section{RESULTS AND DISCUSSION}

\section{Isolation of a 4-CP-degrading micro-organism}

A soil suspension was gradually enriched with 4-CP by successively increasing the 4-CP concentration from 50 to 350 p.p.m. over a period of $165 \mathrm{~d}$. At the end of the adaptation process, the microbial community in the enrichment could degrade a significantly higher concentration of 4-CP than at the start (350 p.p.m. compared to 50 p.p.m.) and the rate of degradation increased from 8 p.p.m. $\mathrm{d}^{-1}$ for the initial substrate addition to $33 \cdot 2$ p.p.m. $\mathrm{d}^{-1}$ for the final addition (data not shown).

Micro-organisms that could grow on 4-CP as sole carbon source were isolated from the enrichment culture. One isolate, hereafter called strain $\mathrm{A} 6^{\mathrm{T}}$, was particularly efficient at 4-CP degradation and was studied further as described below.

The increased tolerance to 4-CP of the enrichment culture demonstrates the usefulness of adaptation processes for selecting micro-organisms with desirable traits; in this case, growth on high concentrations of 4CP. Kramer \& Kory (1992) used a similar approach. They inoculated a 4-CP enrichment culture with sediment and were able to isolate two bacterial strains which could grow on 100 p.p.m. 4-CP in pure culture.

\section{4-CP degradation by strain $\mathbf{A 6}^{\top}$}

Strain $\mathrm{A} 6^{\mathrm{T}}$ was able to grow on up to 350 p.p.m. 4-CP in liquid culture (Fig. $1 \mathrm{a}$ ), using the compound as sole carbon and energy source. The lag phase preceding growth increased with higher concentrations, probably due to toxicity effects. Strain $A 6^{\mathrm{T}}$ also completely removed the 4-CP in the medium during growth (Fig. 1b). The onset of degradation was correlated with the initiation of growth.

When 4-CP was completely removed from the cultures, the $\mathrm{OD}_{600}$ started to decline (Fig. 1 a, b). This was not due to a decrease in cell numbers, as determined by 

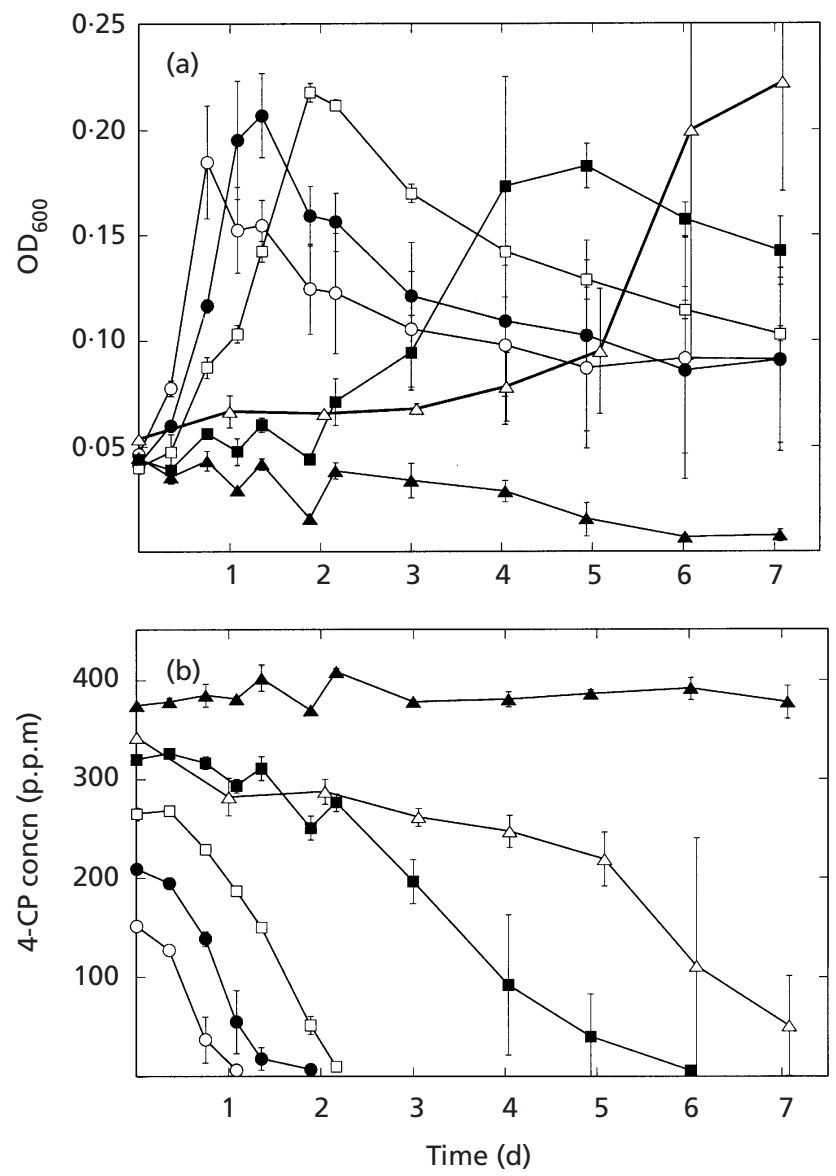

Fig. 1. (a). Growth of strain $A 6^{\top}$ on different concentrations of 4-CP (p.p.m.): $\bigcirc, 150 ; 0,200 ; \square, 250 ; \mathbf{\square}, 320 ; \triangle, 350 ; \Delta, 375$. (b) Removal of different concentrations of 4-CP from culture medium by strain $A 6^{\top}$. Symbols as in (a). Data points are means of three replicates except for the 350 p.p.m. treatment which is in duplicate.

microscopic enumeration, but a transition from a rod morphology to a smaller coccus cell morphology upon entry into stationary phase (data not shown).

To our knowledge, 350 p.p.m. is the highest substrate concentration of 4-CP known to be utilized as sole carbon source by a pure microbial culture. By comparison, the highest 4-CP concentrations previously reported to be degraded were up to 230 p.p.m. by Comamonas testosteroni JH5 (Hollender et al., 1997) and up to 206 p.p.m. by Arthrobacter ureafaciens CPR706 (Bae et al., 1996). In these studies, vitamins or trace amounts of yeast extract, respectively, were routinely added to the culture medium. Chitra et al. (1995) reported a Pseudomonas pictorum HU174 strain able to degrade up to 300 p.p.m. 4-CP in $30 \mathrm{~h}$, but glucose was used as an additional carbon source. None of these carbon or nutrient additions were necessary in our study, since strain $\mathrm{A} 6^{\mathrm{T}}$ only requires a mineral salts medium to grow on 4-CP.

The ability to degrade 4-CP appears to be a stable trait of strain $\mathrm{A}^{\mathrm{T}}$. The organism was serially transferred on
Table 1. Growth and pigment production by strain $A 6^{\top}$ on different aromatic compounds

\begin{tabular}{|lcc|}
\hline Compound & Growth & $\begin{array}{c}\text { Pigment } \\
\text { production }\end{array}$ \\
\hline 4-Chlorophenol & + & + \\
2-Chlorophenol & - & + \\
3-Chlorophenol & - & + \\
2,4-Dichlorophenol & - & + \\
2,4-Dichlorophenoxyacetic acid & - & - \\
Phenol & + & + \\
4-Bromophenol & + & + \\
4-Nitrophenol* & + & + \\
4-Fluorophenol & + & + \\
4-Methylphenol & - & - \\
4-Chlorobenzoate & - & - \\
\hline
\end{tabular}

* Also serves as sole nitrogen source.

non-selective medium (LB), then plated on LB and thereafter tested for the ability of the cells to grow on 4-CP as sole carbon source. The test was performed on cells from the ninth and the tenth transfers for a combined total of 389 colonies. All of these colonies retained the ability to grow on 4-CP, thereby demonstrating that the 4-CP-degrading phenotype was not lost under these non-selective conditions. This is indicative of a chromosomally encoded trait. Furthermore, no plasmid DNA was ever detected from strain $A 6^{\mathrm{T}}$ using a variety of plasmid isolation protocols. Although the lack of a detectable plasmid is not in itself proof of its absence, the evidence leans towards a chromosomally encoded 4-CP phenotype.

\section{Growth on other aromatics and pigment production}

In addition to 4-CP, strain $\mathrm{A} 6^{\mathrm{T}}$ could grow on a number of other para-substituted phenolic compounds (Table 1). 4-Nitrophenol could also be used as sole source of nitrogen. Of the chlorophenols tested, strain $\mathrm{A} 6^{\mathrm{T}}$ could only use 4-CP for growth, further demonstrating a specificity for the para substitution. Growth was restricted to aromatic compounds that are phenols, e.g. 4-chlorobenzoate did not support growth (Table 1).

Specificity for the para position was also found by Bae et al. (1996) who described the Arthrobacter ureafaciens CPR706 strain mentioned above. In addition to 4-CP, it also degrades 4-bromophenol, 4-nitrophenol, 4fluorophenol and 4-iodophenol, but not 2-chlorophenol or 3-chlorophenol. Specificity has also been seen for other positions on the aromatic ring, for example Pseudomonas sp. B13 is able to degrade 3chlorobenzoate, but not 2- or 4-chlorobenzoate. This is due to the narrow substrate specificity of benzoate dioxygenase, the initial enzyme in the pathway. (Dorn et al., 1974; Reineke \& Knackmuss, 1978). One possible explanation for the preference for the para position exhibited by strain $A 6^{\mathrm{T}}$ is that during the 
enrichment on 4-CP, enzymes were recruited, via gene acquisition or mutation, that conferred the ability to degrade a specific range of phenols. For example, Shimp \& Pfaender (1987) saw that an aquatic microbial community that had been adapted to phenol as sole carbon source acquired an increased ability to also degrade 4-CP, 3-methylphenol and 3-aminophenol.

Strain $\mathrm{A} 6^{\mathrm{T}}$ formed pigments from most of the phenolic compounds tested, even those that did not support growth (Table 1) (when testing compounds which could not be used for growth, yeast extract was added to the medium). 4-Methylphenol was the only phenol tested from which pigment was not formed. Interestingly, this compound was also the only parasubstituted phenol tested which strain $A 6^{\mathrm{T}}$ could not grow on. Pigments were only produced from growth substrates when the cultures were incubated without shaking. A possible explanation for this observation could be that pigments are formed under conditions of low oxygen availability, as would be the case in a liquid culture incubated without shaking, whereas when oxygen is plentiful, the phenols are completely degraded. The pigments were initially orange to red in colour, varying somewhat with the substrate for pigment formation, and eventually turning black. The black pigments were insoluble in water and formed a precipitate. The pigments could consist of accumulating intermediate(s) in the 4-CP degradation pathway (Häggblom, 1992). Further characterization of the pigments is under way.

\section{Cellular and metabolic characteristics of strain ${ }^{A} 6^{\top}$}

Strain $\mathrm{A} 6^{\mathrm{T}}$ was characterized as Gram-positive with a rod-coccus life cycle. Spores were not formed, the strain was obligately aerobic and catalase was generated. The cells were motile and the motility was strongly influenced by the type of growth medium; the level of motility increased in rich medium such as LB.

Tests of different growth substrates on plates and/or in liquid culture showed that strain $\mathrm{A} 6^{\mathrm{T}}$ was able to grow on acetate, ethanol, glycerol, creatine, uric acid, succinate, glucose, tyrosine, ascorbic acid, nicotine and weakly on creatinine. Niacin and methanol were not utilized. Blue pigment was not formed, neither on carbohydrate-peptone agar nor on nicotine-yeast extract agar.

A BIOLOG test was performed to investigate which compounds strain $A 6^{\mathrm{T}}$ could use for respiration. The following compounds were utilized for respiration: dextrin, glycogen, D-fructose, D-galactose, D-gluconic acid, $\alpha$-D-glucose, maltose, maltotriose, D-mannose, D-melezitose, D-melibiose, D-psicose, D-raffinose, D-ribose, stachyose, sucrose, turanose, acetic acid, $\beta$-hydroxybutyric acid, $p$-hydroxyphenylacetic acid, $\alpha$ ketoglutaric acid, D-lactic acid methyl ester, L-malic acid, methyl pyruvate, pyruvic acid, $N$-acetyl-Lglutamic acid, D-alanine, L-alanine, L-alanyl-glycine, L-asparagine, L-glutamic acid, L-pyroglutamic acid, Lserine and putrescine. The following substrates were not used for respiration: inulin, $\alpha$-cyclodextrin, $\beta$ cyclodextrin, Tween 40, Tween 80, $N$-acetyl-Dglucosamine, $N$-acetyl-D-mannosamine, amygdalin, L-arabinose, L-arabitol, arbutin, L-fucose, Dgalacturonic acid, $\alpha$-D-lactose, $\beta$-methyl-D-galactoside, $\alpha$-methyl-D-glucoside, $\beta$-methyl-D-glucoside, $\alpha$-methyl-D-mannoside, salicin, sedoheptulosan, D-tagatose, $\gamma$-hydroxybutyric acid, $\alpha$-ketovaleric acid, lactamide, 2,3-butanediol, 2-deoxyadenosine, inosine, thymidine, adenosine-5'-monophosphate, thymidine$5^{\prime}$ monophosphate, uridine-5'-monophosphate, fructose 6-phosphate, glucose 1-phosphate, glucose 6-phosphate and D-L- $\alpha$-glycerol phosphate.

The pattern generated was a good match with Arthrobacter histidinolovorans, the only Arthrobacter species in the BIOLOG database.

\section{Chemotaxonomic analyses}

The cell wall diamino acid was found to be lysine. This finding together with the observation of a rod-coccus life cycle conclusively defined the isolate as an Arthrobacter species (Keddie et al., 1986). Species of some other genera, such as Brevibacterium, Rhodococcus and Aureobacterium, also have a rod-coccus life cycle, but in these genera either ornithine or meso-diaminopimelic acid is the cell wall diamino acid (Keddie et al., 1986).

The peptidoglycan of strain $\mathrm{A} 6^{\mathrm{T}}$ contained Ala, Ser, Thr and Lys in a molar ratio of $2.0: 1.0: 1.0: 1.0$. Enantiomeric analysis of cell wall amino acids resulted in detection of D-Ala, L-Ala, L-Ser, L-Thr and L-Lys. From these results and from two-dimensional TLC peptide patterns of partial hydrolysates of cell walls (data not shown), it was concluded that strain $\mathrm{A6}^{\mathrm{T}}$ contains a peptidoglycan of type A $3 \alpha$ (Schleifer \& Kandler, 1972) with a L-Lys-L-Ser-L-Thr-L-Ala interpeptide bridge (A11.234 DSMZ catalogue, 1998). This interpeptide bridge is unique to two members of the genus Arthrobacter; Arthrobacter oxydans and Arthrobacter polychromogenes. The acyl type was acetyl.

The cellular fatty acid content was consistent with that of the genus Arthrobacter, with anteiso-pentadecanoic acid (15:0 anteiso) predominating (for details, see the species description below). By contrast, in the related genus Brevibacterium, both 15:0 anteiso and 17:0 anteiso predominate (Funke \& Carlotti, 1994). However, the fatty acid content gave little information as to which species the isolate belonged to, since the fatty acid content is very similar between species in the genus Arthrobacter. Several authors have found it impossible to distinguish between different Arthrobacter species based on fatty acid data (Funke et al., 1996; Koch et al., 1995; Kodama et al., 1992).

\section{Genetic analyses}

The melting temperature of the genomic DNA of strain $\mathrm{A} 6^{\mathrm{T}}$ was found to be $82.4^{\circ} \mathrm{C}$, giving a $\mathrm{G}+\mathrm{C}$ content of $65.1 \mathrm{~mol} \%$. This value is characteristic for 


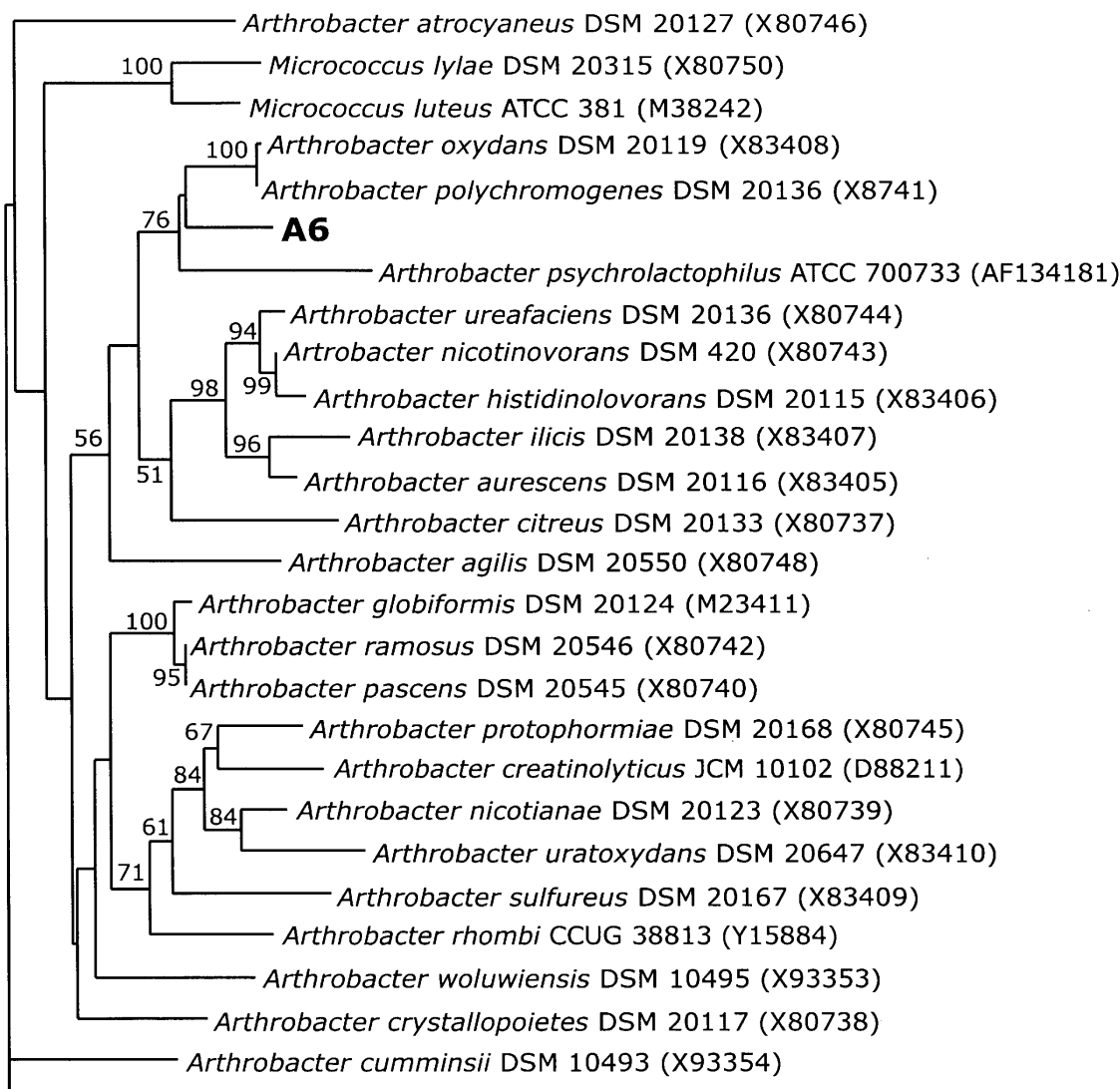

Mycobacterium tuberculosis RF4738 (X52917)

0.01

Fig. 2. Phylogenetic tree constructed from the $16 \mathrm{~S}$ rDNA sequences of strain $A 6^{\top}$ and its 24 closest relatives. Mycobacterium tuberculosis was used as an outgroup. The numbers at the forks show how many times the group to the right of the fork occurred among the 100 trees generated in a bootstrap analysis. Only values $>50$ are shown. The bar represents 1 expected substitution per $100 \mathrm{nt}$. The culture collection accession number and the GenBank accession number (in parentheses) is indicated for each strain.

Arthrobacter species, which typically have a $\mathrm{G}+\mathrm{C}$ content in the range of 59-70\% (Keddie et al., 1986).

The 16S rDNA of strain $\mathrm{A}^{\mathrm{T}}$ was cloned and sequenced, revealing that the closest relatives were Arthrobacter polychromogenes and Arthrobacter oxydans, both with a sequence similarity to strain $\mathrm{A}^{\mathrm{T}}$ of $97.5 \%$ (with gaps included and treated as a fifth nucleotide). Such a value is typical for interspecies differences in the genus Arthrobacter (Funke et al., 1996). Stackebrandt \& Goebel (1994) note that at a sequence homology of about $97.5 \%$, it is unlikely that two organisms are related at the species level, this percentage being indicative of moderately related species.

A phylogenetic tree was constructed based on the $16 \mathrm{~S}$ rDNA sequence of strain $A 6^{\mathrm{T}}$ and those of its closest relatives, using Mycobacterium tuberculosis as an outgroup (Fig. 2). Bootstrap analysis showed that many branching points could not be considered statistically significant, which has also been found by other authors (Funke et al., 1996; Koch et al., 1995).
Strain $\mathrm{A}^{\mathrm{T}}$ clustered with Arthrobacter oxydans and Arthrobacter polychromogenes in the phylogenetic tree (Fig. 2), in accordance with the finding that strain $A 6^{\mathrm{T}}$ had the same peptidoglycan interpeptide bridge as these two species.

According to the phylogenetic tree, strain $\mathrm{A} 6^{\mathrm{T}}$ is also closely related to Arthrobacter psychrolactophilus. However, strain $\mathrm{A} 6^{\mathrm{T}}$ appears to be less related to this organism than to Arthrobacter oxydans and Arthrobacter polychromogenes, since the similarity of the $16 \mathrm{~S}$ rDNA between strain A6 $6^{\mathrm{T}}$ and Arthrobacter psychrolactophilus is lower $(96.0 \%$, gaps treated as a fifth nucleotide).

To decide whether strain $A 6^{\mathrm{T}}$ should be classified as the type strain of a novel Arthrobacter species or whether it should be affiliated to either Arthrobacter oxydans or Arthrobacter polychromogenes, DNADNA reassociation values were determined for strain A $6^{\mathrm{T}}$ and type strains of the two described species. While the latter two strains share $66 \%$ similarity, strain $\mathrm{A}^{\mathrm{T}}$ is significantly less related to either of them, 
Table 2. Distinguishing characteristics between strain $A 6^{\top}$ and its closest relatives

Data are from this study, Keddie et al. (1986), Loveland-Curtze et al. (1999), Schippers-Lammertse et al. (1963) and Sguros (1955). NA, Not applicable.

\begin{tabular}{|c|c|c|c|c|}
\hline Trait & Strain $\mathbf{A 6}^{\mathrm{T}}$ & A. oxydans & A. polychromogenes & A. psychrolactophilus \\
\hline Serine in cell wall & Yes & Yes & Yes & No \\
\hline $\begin{array}{l}\text { Colony pigmentation on } \\
\text { peptone-carbohydrate medium }\end{array}$ & Pearl grey & $\begin{array}{l}\text { Pearl grey to } \\
\text { yellow }\end{array}$ & Blue & Cream to yellow \\
\hline Growth on nicotine & Yes & Yes & No & No \\
\hline $\begin{array}{l}\text { Colony pigmentation on } \\
\text { nicotine-yeast extract agar }\end{array}$ & Pearl grey & Blue & NA & NA \\
\hline $\begin{array}{l}\text { Growth in mineral salts medium } \\
\text { without biotin }\end{array}$ & Yes & No & No & Yes \\
\hline Growth at $37^{\circ} \mathrm{C}$ & Yes & Yes & Yes & No \\
\hline Temperature range & $3-37^{\circ} \mathrm{C}$ & Not reported & $10-37^{\circ} \mathrm{C}$ & $0-30{ }^{\circ} \mathrm{C}$ \\
\hline Motile & Yes & No & No & No \\
\hline Isolation source & Soil & $\begin{array}{l}\text { Tobacco } \\
\text { leaves and air }\end{array}$ & Airborne infection & Soil \\
\hline
\end{tabular}

sharing $52 \%$ and $41 \%$ similarity with Arthrobacter oxydans DSM 20119 ${ }^{\mathrm{T}}$ and Arthrobacter polychromogenes DSM 20136 ${ }^{\mathrm{T}}$, respectively.

DNA-DNA hybridization is thought to be the best method to determine relationships between strains, and when the reassociation values are less than $70 \%$, the strains are considered to belong to different species (Wayne et al., 1987). Thus, both $16 \mathrm{~S}$ similarity values and DNA-DNA reassociation values obtained for strain A6 ${ }^{\mathrm{T}}$, Arthrobacter oxydans DSM 20119 ${ }^{\mathrm{T}}$ and Arthrobacter polychromogenes DSM 20136 ${ }^{\mathrm{T}}$ cluster the latter two strains while strain $A 6^{\mathrm{T}}$ is more distantly related. These findings support the description of strain A $6^{\mathrm{T}}$ as the type strain of a new Arthrobacter species.

\section{Comparison of strain $\mathrm{A}^{\top}{ }^{\top}$ with phylogenetic neighbours}

In addition to differences at the DNA level, strain $A 6^{\mathrm{T}}$ can also be distinguished from its closest relatives based on a number of other characteristics (Table 2). The finding from DNA sequence data that strain $\mathrm{A}^{\mathrm{T}}$ is more closely related to Arthrobacter oxydans and Arthrobacter polychromogenes than to Arthrobacter psychrolactophilus is supported by the finding that strain $A 6^{\mathrm{T}}$ has the same type of peptidoglycan composition as the two former species, while Arthrobacter psychrolactophilus differs in lacking serine. Interestingly, strain $\mathrm{A}^{\mathrm{T}}$, like Arthrobacter oxydans, is capable of growth on nicotine, although strain $A 6^{\mathrm{T}}$ was not isolated from any nicotine-containing environment. However, strain A6 $6^{\mathrm{T}}$ differs from Arthrobacter oxydans in that it does not form a blue pigment on nicotine-yeast extract agar. Neither does strain $A 6^{\mathrm{T}}$ form the blue colony pigment on carbohydratepeptone medium, a feature typical of Arthrobacter polychromogenes. The temperature growth range also differs between the strains (Table 2). Strain A6 ${ }^{\mathrm{T}}$ grows at a comparatively wide range of temperatures (3$37^{\circ} \mathrm{C}$ ). Arthrobacter psychrolactophilus is not able to grow at $37^{\circ} \mathrm{C}$ and the lowest reported growth temperature of Arthrobacter oxydans is $10^{\circ} \mathrm{C}$. Furthermore, strain $\mathrm{A} 6^{\mathrm{T}}$ and Arthrobacter psychrolactophilus, unlike Arthrobacter oxydans and Arthrobacter polychromogenes, can grow in mineral salts medium with ammonium or nitrate as sole nitrogen source, while the latter two require vitamins such as biotin. Another distinguishing characteristic is motility, since strain A $6^{\mathrm{T}}$ is the only one of these strains which is motile. Finally, the sources of isolation differ. Whereas Arthrobacter oxydans and Arthrobacter polychromogenes were isolated from tobacco leaves and air, respectively, strain $\mathrm{A}^{\mathrm{T}}$ and Arthrobacter psychrolactophilus were isolated from soil.

Since species of the genus Arthrobacter are among the most common bacteria in soil (Keddie et al., 1986), it is not surprising that our soil isolate was found to be an Arthrobacter species. Soil is generally considered to be a harsh environment with fierce competition for resources. Members of the genus Arthrobacter appear well adapted to this habitat, as they are resistant to both starvation and desiccation, and are capable of utilizing a wide range of carbon sources (Ensign, 1970; Keddie et al., 1986). The nutritional versatility of this genus is also reflected in the fact that they have been found to degrade several other pollutants in addition to 4-CP, for example chlorinated phenoxyalkanoic herbicides such as 2,4-D (Häggblom, 1992), polychlorinated biphenyls (Abramowicz, 1990) and petroleum hydrocarbons (Leahy \& Colwell, 1990).

\section{Conclusions}

We have isolated a micro-organism which is promising for bioremediation of 4-CP since it degrades unusually high concentrations of the compound. Moreover, no 
additional growth factors are required and the 4-CP degradation phenotype is stable. All of the available taxonomic evidence indicates that strain $\mathrm{A} 6^{\mathrm{T}}$ is a novel species within the genus Arthrobacter and we propose the name Arthrobacter chlorophenolicus sp. nov.

\section{Description of Arthrobacter chlorophenolicus sp. nov.}

Arthrobacter chlorophenolicus (chlor.o.phen.o'li.cus. M.L. adj. chloro containing chlorine, N.L. n. phenol phenol; M.L. adj. chlorophenolicus relating to chlorophenols).

Cells are Gram-positive and display a rod-coccus life cycle. The cocci are $\sim 0.75 \mu \mathrm{m}$ in diameter. The rods are $\sim 0.5-0.7 \mu \mathrm{m}$ wide, while the length varies between 1 and $4 \mu \mathrm{m}$, depending on stage in the life cycle and composition of the growth medium. Agar colonies are circular, smooth and pearl grey in colour. Spores are not formed. Growth occurs with a suitable carbon source in mineral salts medium, no additional growth factors are needed. Red to black pigment is formed from several phenolic compounds, only during incubation with shaking from phenols that can be used for growth, and both with and without shaking for phenols that cannot be used for growth. Catalasepositive. Motile. Obligately aerobic. Grows at $3-37^{\circ} \mathrm{C}$, optimum between 20 and $30^{\circ} \mathrm{C}$. Grows on acetate, ethanol, glycerol, creatine, uric acid, succinate, glucose, tyrosine, ascorbic acid, nicotine and weakly on creatinine. Niacin and methanol are not utilized. A BIOLOG test showed that the following compounds were utilized for respiration: dextrin, glycogen, Dfructose, D-galactose, D-gluconic acid, $\alpha$-D-glucose, maltose, maltotriose, D-mannose, D-melezitose, Dmelibiose, D-psicose, D-raffinose, D-ribose, stachyose, sucrose, turanose, acetic acid, $\beta$-hydroxybutyric acid, $p$-hydroxyphenylacetic acid, $\alpha$-ketoglutaric acid, Dlactic acid methyl ester, L-malic acid, methyl pyruvate, pyruvic acid, $N$-acetyl-L-glutamic acid, D-alanine, L-alanine, L-alanyl-glycine, L-asparagine, L-glutamic acid, L-pyroglutamic acid, L-serine and putrescine. The following substrates were not used for respiration: inulin, $\alpha$-cyclodextrin, $\beta$-cyclodextrin, Tween 40, Tween $80, \quad N$-acetyl-D-glucosamine, $N$-acetyl-Dmannosamine, amygdalin, L-arabinose, L-arabitol, arbutin, L-fucose, D-galacturonic acid, $\alpha$-D-lactose, $\beta$-methyl-D-galactoside, $\alpha$-methyl-D-glucoside, $\beta$ methyl-D-glucoside, $\alpha$-methyl-D-mannoside, salicin, sedoheptulosan, D-tagatose, $\gamma$-hydroxybutyric acid, $\alpha$ ketovaleric acid, lactamide, 2,3-butanediol, 2-deoxyadenosine, inosine, thymidine, adenosine-5'-monophosphate, thymidine $-5^{\prime}$ monophosphate, uridine- $5^{\prime}$ monophosphate, fructose 6-phosphate, glucose 1phosphate, glucose 6-phosphate and D-L- $\alpha$-glycerol phosphate. The $\mathrm{G}+\mathrm{C}$ content is $65.1 \mathrm{~mol} \%$. The cellular fatty acid content is as follows: 15:0 anteiso, $66 \% ; 16: 0$ iso, $10 \% ; 15: 0$ iso, $7 \% ; 17: 0$ anteiso, $5 \%$; $14: 0$ iso, $4 \% ; 16: 0,3 \% ; 14: 0,2 \% ; 16: 1$ iso $h, 1 \%$; $16: 1 \omega 7 c, 1 \%$; anteiso $17: 1 \omega 9 c, 1 \%$ (only values $\geqslant 1 \%$ are reported). The cell wall diamino acid is lysine. The peptidoglycan type is A $3 \alpha$ (Schleifer \& Kandler, 1972), with an L-Lys-L-Ser-L-Thr-L-Ala interpeptide bridge. Arthrobacter chlorophenolicus $\mathrm{A} 6^{\mathrm{T}}$ was isolated from soil at Fort Collins, CO, USA. The type strain $\left(\mathrm{A} 6^{\mathrm{T}}\right)$ has been deposited at the DSMZ as DSM $12829^{\mathrm{T}}$.

\section{ACKNOWLEDGEMENTS}

The authors gratefully acknowledge Frans J. deBrujin at Michigan State University, East Lansing, MI, USA, for initial sequencing of part of the $16 \mathrm{~S}$ rDNA, Kirsten S. Jørgensen at the Finnish Environment Institute, Helsinki, Finland, for doing the BIOLOG analysis, Mirja SalkinojaSalonen at the University of Helsinki, Helsinki, Finland, for doing the fatty acid analysis, Ulrike Steiner and Norbert Weiss at the DSMZ for determination of DNA similarities and analysis of the peptidoglycan, respectively, and Vigdis Torsvik at the University of Bergen, Bergen, Norway, for the $\mathrm{G}+\mathrm{C}$ determination. This research was funded by the Carl Tryggers Foundation, the Swedish Foundation for Strategic Research, the Swedish Council for Engineering Science and the Swedish Foundation for Environmental Research.

\section{REFERENCES}

Abramowicz, D. A. (1990). Aerobic and anaerobic biodegradation of PCBs: a review, Crit Rev Biotechnol 10, 241-251.

Alexander, M. \& Lustigman, B. K. (1966). Effect of chemical structure on microbial degradation of substituted benzenes, J Agric Food Chem 14, 410-413.

Bae, H. S., Lee, J. M. \& Lee, S. T. (1996). Biodegradation of 4chlorophenol via a hydroquinone pathway by Arthrobacter ureafaciens CPR706, FEMS Microbiol Lett 145, 125-129.

Brandsch, R. \& Decker, K. (1984). Isolation and partial characterization of plasmid DNA from Arthrobacter oxydans, Arch Microbiol 138, 15-17.

Brosius, J., Palmer, M. L., Kennedy, J. P. \& Noller, H. F. (1978). Complete nucleotide sequence of a $16 \mathrm{~S}$ ribosomal RNA gene from Escherichia coli, Proc Natl Acad Sci USA 75, 4801-4805.

Cashion, P., Holder-Franklin, M. A., McCully, J. \& Franklin, M. (1977). A rapid method for the base ratio determination of bacterial DNA, Anal Biochem 81, 461-466.

Chitra, S., Sekaran, G., Padmavathi, S. \& Chandrakasan, G. (1995). Removal of compounds from wastewater using mutant strain of Pseudomonas pictorum, J Gen Appl Microbiol 41, 229-237.

De Ley, J., Cattoir, H. \& Reynaerts, A. (1970). The quantitative measurement of DNA hybridisation from renaturation rates, Eur J Biochem 12, 133-142.

Dorn, E., Hellwig, M., Reineke, W. \& Knackmuss, H. J. (1974). Isolation and characterization of a 3-chlorobenzoate degrading pseudomonad, Arch Microbiol 99, 61-70.

Eckhardt, T. (1978). A rapid method for the identification of plasmid deoxyribonucleic acid, Plasmid 1, 584-588.

Ensign, J. C. (1970). Long-term starvation survival of rod and spherical cells of Arthrobacter crystallopoietes, J Bacteriol 103, 569-577.

Escara, J. F. \& Hutton, J. R. (1980). Thermal stability and renaturation of DNA in dimethylsulfoxide solutions: acceleration of renaturation rate, Biopolymers 19, 1315-1327. 
Felsenstein, J. (1985). Confidence limits on phylogenies: an approach using the bootstrap, Evolution 39, 783-791.

Felsenstein, J. (1993). PHYLIP (Phylogeny Inference Package) version 3.5.1. Seattle: Department of Genetics, University of Washington.

Funke, G. \& Carlotti, A. (1994). Differentiation of Brevibacterium spp. encountered in clinical specimens, J Clin Microbiol 32, 1729-1732.

Funke, G., Hutson, R. A., Bernard, K. A., Pfyffer, G. E., Wauters, G. \& Collins, M. D. (1996). Isolation of Arthrobacter spp. from clinical specimens and description of Arthrobacter cumminsii sp. nov. and Arthrobacter woluwiensis sp. nov, J Clin Microbiol 34, 2356-2363.

Häggblom, M. M. (1990). Mechanisms of bacterial degradation and transformation of chlorinated monoaromatic compounds, $J$ Basic Microbiol 2, 115-141.

Häggblom, M. M. (1992). Microbial breakdown of halogenated aromatic pesticides and related compounds, FEMS Microbiol Rev 103, 29-72.

Hill, G. A., Milne, B. J. \& Nawrocki, P. A. (1996). Cometabolic degradation of 4-chlorophenol by Alcaligenes eutrophus, Appl Microbiol Biotechnol 46, 163-168.

Hollender, J., Hopp, J. \& Dott, W. (1997). Degradation of 4chlorophenol via the meta cleavage pathway by Comamonas testosteroni JH5, Appl Environ Microbiol 63, 4567-4572.

Huß, V. A. R., Festl, H. \& Schleifer, K. H. (1983). Studies on the spectrophotometric determination of DNA hybridization from renaturation rates, Syst Appl Microbiol 4, 184-192.

Ihn, W., Janke, D. \& Tresselt, D. (1989). Critical steps in degradation of chloroaromatics by rhodococci. J, Basic Microbiol 29, 291-297.

Jahnke, K.-D. (1992). BASIC computer program for evaluation of spectroscopic DNA renaturation data from Gilford System 2600 spectrophotometer on a PC/XT/AT type personal computer, J Microbiol Methods 15, 61-73.

Jukes, T. H. \& Cantor, C. R. (1969). Evolution of protein molecules. In Mammalian Protein Metabolism, pp. 21-132. Edited by H. N. Munro. New York: Academic Press.

Keddie, R. M., Collins, M. D. \& Jones, D. (1986). Genus Arthrobacter Conn and Dimmick 1947, 300 ${ }^{\mathrm{AL}}$. In Bergey's Manual of Systematic Bacteriology, pp. 1228-1301. Edited by P. H. A. Sneath, N. S. Mair, M. E. Sharpe \& J. G. Holt. Baltimore: Williams \& Wilkins.

Koch, C., Schumann, P. \& Stackebrandt, E. (1995). Reclassification of Micrococcus agilis (Ali-Cohen 1889) to the genus Arthrobacter as Arthrobacter agilis comb. nov. and emendation of the genus Arthrobacter, Int J Syst Bacteriol 45, 837-839.

Kodama, Y., Yamamoto, H., Amano, N. \& Amachi, T. (1992). Reclassification of two strains of Arthrobacter oxydans and proposal of Arthrobacter nicotinovorans sp. nov, Int J Syst Bacteriol 42, 234-239.

Kramer, C. M. \& Kory, M. M. (1992). Bacteria that degrade $p$ chlorophenol isolated from a continuous culture system, Can J Microbiol 38, 34-37.

Leahy, J. G. \& Colwell, R. R. (1990). Microbial degradation of hydrocarbons in the environment, Microbiol Rev 54, 305-315.

Liu, S. \& Suflita, J. M. (1993). Ecology and evolution of microbial populations for bioremediation, Trends Biotechnol 11, 344-352.

Loveland-Curtze, J., Sheridan, P. P., Gutshall, K. R. \& Brenchley, J. E. (1999). Biochemical and phylogenetic analyses of psychrophilic isolates belonging to the Arthrobacter subgroup and description of Arthrobacter psychrolactophilus, sp. nov, Arch Microbiol 171, 355-363.

Madsen, T. \& Aamand, J. (1992). Anaerobic transformation and toxicity of trichlorophenols in a stable enrichment culture, Appl Environ Microbiol 58, 557-561.

Maidak, B. L., Larsen, N., McCaughey, M. J., Overbeek, R., Olsen, G. J., Foge, K., Blandy, J. \& Woese, C. R. (1994). The ribosomal database project, Nucleic Acids Res 22, 3485-3487.

Mandel, M., Igambi, L., Bergendahl, J., Dodson, M. L., Jr \& Scheltgen, E. (1970). Correlation of melting temperature and cesium chloride buoyant density of bacterial deoxyribonucleic acid, J Bacteriol 101, 333-338.

Meynell, G. G. \& Meynell, E. (1970). Theory and Practice in Experimental Bacteriology 2nd edn. Cambridge: Cambridge University Press.

Pritchard, P. H., O'Neill, E. J., Spain, C. M. \& Ahearn, D. J. (1987). Physical and biological parameters that determine the fate of $p$ chlorophenol in laboratory test systems, Appl Environ Microbiol 53, 1833-1838.

Reineke, W. \& Knackmuss, H.-J. (1978). Chemical structure and biodegradability of halogenated aromatic compounds. Substituent effects on 1,2-dioxygenation of benzoic acid, Biochim Biophys Acta 542, 412-423.

Sambrook, J., Fritsch, E. F. \& Maniatis, T. (1989). Molecular Cloning : a Laboratory Manual, 2nd edn. Cold Spring Harbor, NY : Cold Spring Harbor Laboratory.

Schippers-Lammertse, A. F., Muijsers, A. O. \& Klatser-Odekerk, K. B. (1963). Arthrobacter polychromogenes nov. spec., its pigments, and a bacteriophage of this species, Antoine Leeuwenhoek 29, 1-15.

Schleifer, K. H. \& Kandler, O. (1972). Peptidoglycan types of bacterial cell walls and their taxonomic implications, Bacteriol Rev 36, 407-477.

Sguros, P. L. (1955). Microbial transformations of the tobacco alkaloids. I. Cultural and morphological characteristics of a nicotinophile, J Bacteriol 69, 28-37.

Shimp, R. J. \& Pfaender, F. K. (1987). Effect of adaptation to phenol on biodegradation of monosubstituted phenols by aquatic microbial communities, Appl Environ Microbiol 53, 1496-1499.

Stackebrandt, E. \& Goebel, B. M. (1994). Taxonomic note: a place for DNA-DNA reassociation and 16S rRNA sequence analysis in the present species definition in bacteriology, Int $J$ Syst Bacteriol 44, 846-849.

Staneck, J. L. \& Roberts, G. D. (1974). Simplified approach to identification of aerobic actinomycetes by thin-layer chromatography, Appl Microbiol 119, 226-230.

Timmis, K. N. \& Pieper, D. H. (1999). Bacteria designed for bioremediation, Trends Biotechnol 17, 201-204.

Väisänen, O. M., Nurmiaho-Lassila, E.-L., Marmo, S. A. \& Salkinoja-Salonen, M. S. (1994). Structure and composition of biological slimes on paper and board machines, Appl Environ Microbiol 60, 641-653.

van Veen, J. A., van Overbeek, L. S. \& van Elsas, J. D. (1997). Fate and activity of microorganisms introduced into soil, Microbiol Mol Biol Rev 61, 121-135.

Wayne, L. G., Brenner, D. J., Colwell, R. R. \& 9 other authors (1987). International Committee on Systematic Bacteriology. Report of the ad hoc committee on reconciliation of approaches to bacterial systematics. Int J Syst Bacteriol 37, 463-464.

Weisburg, W. G., Barns, S. M., Pelletier, D. A. \& Lane, D. J. (1991). 
16S ribosomal DNA amplification for phylogenetic study, $J$ Bacteriol 173, 697-703.

Wieser, M., Eberspächer, J., Vogler, B. \& Lingens, F. (1994). Metabolism of 4-chlorophenol by Azotobacter sp. GP1: Structure of the meta cleavage product of 4-chlorocatechol, FEMS Microbiol Lett 116, 73-78.
Vogel, T. M. (1996). Bioaugmentation as a soil bioremediation approach, Curr Opin Biotechnol 7, 311-316.

Woods, S. L., Ferguson, J. F. \& Benjamin, M. M. (1989). Characterization of chlorophenol and chloromethoxybenzene biodegradation during anaerobic treatment, Environ Sci Technol 23, 62-68. 